Available online at http://jurnal.upmk.ac.id/index.php/lensapendas

\title{
PEMANFAATAN LINGKUNGAN SEKOLAH SEBAGAI SUMBER BELAJAR MATA PELAJARAN ILMU PENGETAHUAN ALAM ( IPA ) SISWA KELAS IV SDN 1 CILEUYA KECAMATAN CIMAHI KABUPATEN KUNINGAN
}

Firda Sari Ayuningsih ${ }^{1}$, Irfan Fajrul Falah ${ }^{2}$

Pendidikan Guru Sekolah Dasar, STKIP Muhammadiyah Kuningan

irfan_fajrul@upmk.ac.id

\section{Info Artikel}

\section{Sejarah Artikel:}

Diterima Bulan Januari, 2020

Dipublikasikan Bulan

Februari, 2020

Keywords:

Pembelajaran IPA, Sumber Belajar

Natural Sciences

Learning, Learning

Resources

Abstrak

Tujuan dari penelitian ini adalah untuk mengetahui bagaimana proses pembelajaran dengan memanfaatkan lingkungan sekolah sebagai sumber belajar pada mata pelajaran IPA di kelas IV SDN 01 Cileuya, dan untuk mengetahui peran serta kendala yang menghambat proses pemanfaatan lingkungan sekolah sebagai sumber belajar pada mata pelajaran IPA dikelas IV SDN I Cileuya. Penelitian ini menggunakan metode kualitatif dengan desain penelitian studi kasus, dengan menggunakan responden siswa kelas IV, guru/ wali kelas IV. Teknik pengumpulan data yang digunakan yaitu wawancara, observasi dan dokumentasi, sementara untuk teknik analisis data yang digunakan peneliti adalah triangulasi. Hasil penelitian ini menyatakan bahwa dengan guru menerapkan lingkungan sekolah sebagai sumber belajar pada pembelajaran IPA dapat membuat suasana pembelajaran menjadi menyenangkan, karena lingkungan sekolah sangatlah berperan penting dalam proses pembelajaran, khususnya pada pembelajaran IPA yang erat kaitanya dengan lingkungan sekitar. Namun adapula beberapa kendala yang mengambat seperti dalam pengelolaan waktu dan kurangnya konsentrasi siswa.

\section{Abstract}

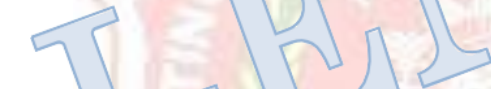

The purpose of this research is to find out how the learning process by utilizing the school environment as a learning resource in natural science subjects in class IV SDNOI Cileuya, and to find out the role and constraints that hamper the process of utilizing the school environment as a learning resource in natural science subjects in class IV SDN I Cileuya. This study used a qualitative method with a case study research design, using respondents in class IV, class IV teachers / guardians. Data collection techniques used were interviews, observation and documentation, while the data analysis technique used by researchers was triangulation. The results of this study state that the teacher applies the school environment as a source of learning in science learning can make the learning atmosphere enjoyable, because the school environment plays an important role in the learning process, especially in science learning which is closely related to the surrounding environment. But there are some obstacles that hamper such as time management and lack of student concentration.

(C) 2020 Firda Sari Ayuningsih ${ }^{1}$, Irfan Fajrul Falah ${ }^{2}$. Under the license CC BY-SA 4.0

Alamat Korespondensi Email

\author{
: STKIP Muhammadiyah Kuningan \\ : Irfan_fahrul@upmk.ac.id
}


Jurnal Lensa Pendas, Vol. 5 Nomor 2 Tahun 2020, HIm 15 - 23

Firda Sari Ayuningsih ${ }^{1}$, Irfan Fajrul Falah ${ }^{2}$

\section{PENDAHULUAN}

Pendidikan merupakan usaha yang dilakukan dengan sengaja dan sistematis untuk memotivasi, membina, membantu, serta membimbing seseorang untuk mengembangkan segala potensinya sehingga bisa mencapai kualitas diri yang lebih baik. ( Tatang, 2012: 15 ) Inti pendidikan adalah usaha pendewasaan manusia seutuhnya,baik oleh dirinya maupun orang lain, Dalam arti tuntutan agar anak didik memiliki kemerdekaan berfikir, merasa, berbicara, dan bertindak serta percaya diri dengan penuh rasa tanggung jawab dalam setiap tindakan dan perilaku sehari-hari.

Salah satu upaya untuk meningkatkan mutu pendidikan adalah dengan cara memperbaiki proses pembelajaran. Menurut (Ali Mudlofir dkk, 2017: 193) salah satu faktor yang dapat menunjang keberhasilan proses pembelajaran adalah pemilihan sumber belajar yang mendukung proses pembelajaran.

$$
\text { Pembelajaran Ilmu }
$$

Pengetahuan Alam (IPA), merupakan salah satu pembelajaran inovatif yang berkaitan erat dengan alam sekitar, mengarahkan guru untuk menggunakan lingkungan sebagai sumber belajar. Dengan memanfaatkan lingkungan sebagai salah satu sumber belajar IPA, maka diharapkan dapat membantu meningkatkan mutu pembelajaran dalam proses pembelajaran. Lingkungan mempunyai peran penting dalam proses pembelajaran IPA di Sekolah
Dasar, karena lingkungan dapat berfungsi sebagai sasaran belajar, sumber belajar, maupun sarana belajar IPA.

Menurut Djanali (2007 : 279) mengatakan bahwa sumber belajar paling dekat dengan anak adalah lingkungan, karena lingkungan adalah insprirasi dan ide yang tiada batasnya.

$$
\text { Pemanfaatan lingkungan }
$$

sekolah sebagai sumber belajar juga memberikan pengalaman yang nyata kepada siswa, sehingga konsep materi pelajaran akan lebih tertanam lagi dalam benak siswa dan juga memberikan pembelajaran yang inovatif serta menyenangkan sehingga tidak cepat bosan dalam mengikuti kegiatan pembelajaran. Hal ini senada dengan pendapat Rusman (2014 : 193) bahwa pengetahuan teoritis yang bersifat hapalan mudah lepas dari ingatan seseorang apabila tidak ditunjang dengan pengalaman nyata. Maka dari itu dengan memanfaatkan lingkungan sekolah sebagai sumber belajar dapat mengatasi permasalahan diatas yang berkaitan dengan interaksi dan motivasi belajar siswa yang ditunjang dengan pengalaman nyata. Berdasarkan latar belakang di atas, peneliti tertarik untuk melakukan penelitian ini. Maka, dalam penelitian ini akan difokuskan kepada pemanfaatan lingkungan sebagai sumber belajar. Sehingga penelitian ini diberi judul : " Pemanfaatan Lingkungan Sekolah Sebagai Sumber Belajar Mata Pelajaran Ilmu Pengetahuan Alam ( IPA ) Siswa kelas IV SD Negeri 1 Cileuya " 


\section{Jurnal Lensa Pendas, Vol. 5 Nomor 2 Tahun 2020, HIm 15 - 23}

Firda Sari Ayuningsih ${ }^{1}$, Irfan Fajrul Falah ${ }^{2}$

\section{METODE PENELITIAN}

Dalam penelitian ini, peneliti menggunakan metode kualitatif . Menurut Bogdan dan Taylor (dalam Moeleong, 2007: 4) metode kualitatif adalah prosedur penelitian yang menghasilkan data deskriptif berupa kata-kata tertulis atau lisan dari orangorang dan perilaku yang dapat diamati. Sejalan dengan itu, David Wiliam (dalam Moeleong, 2007: 5) menyatakan bahwa penelitan kualitatif adalah pengumpulan data pada suatu latar alamiah, dengan menggunakan metode alamiah, dan dilakukan oleh orang atau peneliti yang tertarik secara alamiah.

Dari definisi- definisi diatas dapat disimpulkan bahwa penelitian kualitatif adalah penelitian yang bermaksud untuk memahami fenomena tentang apa yang dialami oleh subjek penelitian misalnya perilaku, persepsi, motivasi, dan tindakan dengan cara menggunakan metode alamiah. Dalam penelitian kualitatif ini, peneliti menggunakan pendekatan kualitatif studi kasus (Case Study).

Menurut maxfield ( dalam Ihat Hatimah dkk, 2007 : 94) penelitian studi kasus ( Case Study) adalah penelitian yang berkenaan dengan suatu fase spesifik atau khas dari keseluruhan personalitas. Secara khusus pendekatan kualitatif studi kasus (Case Study) dipilih karena peneliti merasa bahwa pendekatan kualitatif studi kasus (Case Study) ini tepat digunakan untuk memperoleh gambaran dan pemahaman secara mendalam tentang pemnafaatan lingkungan sekolah sebagai salah satu sumber belajar bagi siswa sekolah dasar.

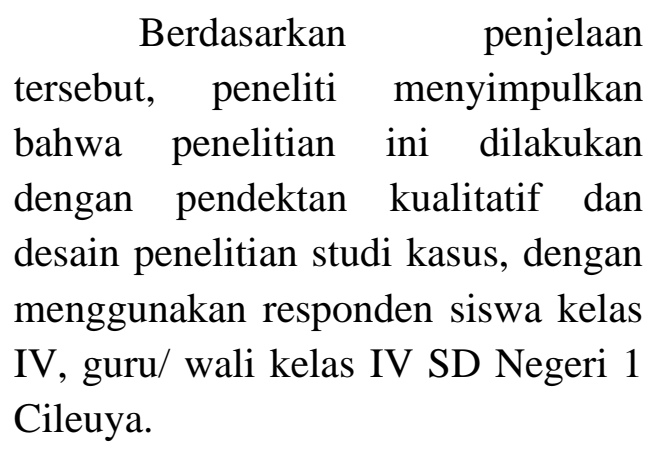

Menurut Lofland dan Lofland (dalam Moleong, 2007 : 157 ) sumber data utama dalam penelitian ialah kata- kata dan tindakan, selebihnya adalah data tambahan seperti dokumen dan lain-lain. Data yang dihimpun peneliti dalam penelitian ini secara garis besar dibagi menjadi dua bagian yaitu sumber data primer dan sumber data sekunder. 1. Sumber data primer

Menurut Umi Narimawati ( 2008 : 98) sumber data primer adalah sumber data yang langsung memberikan data kepada pungumpul data. Data primer juga merupakan pengambilan data dengan instrumen pengamatan, wawancara, catatan lapangan, dan penggunaan dokumen. Adapun dalam penelitian ini sumber data primer adalah warga sekolah yang meliputi : Guru kelas, siswa/ siswi kelas IV SDN 01 Cileuya.

2. Data sekunder

Menurut Umi Narimawati ( 2008 : 98) 


\section{Jurnal Lensa Pendas, Vol. 5 Nomor 2 Tahun 2020, HIm 15 - 23}

Firda Sari Ayuningsih ${ }^{1}$, Irfan Fajrul Falah ${ }^{2}$

sumber data sekunder merupakan

sumber yang tidak langsung memberikan data kepada pengumpul data, misalnya lewat orang lain atau dokumen. Sumber data sekunder digunakan untuk mendukung data primer yaitu melalui studi kepustakaan, dokumentasi, buku majalah, koran, arsip tertulis atau obyek lain yang akan diteliti pada penelitian ini. Adapun sumber data sekunder dalam penelitian ini adalah lingkungan sekolah yang dimanfaatkan sebagai salah satu sumber belajar khususnya pada mata pelajaran Ilmu Pengetahuan Alam ( IPA).

\section{HASIL PENELITIAN DAN PEMBAHASAN}

Pada bagian ini dijelaskan hasil-hasil penelitian dalam bentuk paragraf-paragraf sekaligus diberikan pembahasan yang komprehensif. Hasil dapat disajikan dalam bentuk gambar, grafik, tabel dan lain-lain yang memudahkan pembaca.

Pemanfaatan lingkungan sekolah sebagai sumber belajar dapat dilakukan dalam rangka mengembangkan potensi siswa untuk melakukan kegiatan di luar kelas untuk menemukan sebab-sebab sebuah kejadian di sekitarnya, serta mencari hubungan antara fakta-fakta yang ada di lingkungan fisiknya. Informan penelitian pertama bernama Bapak Casta S.Pd SD, Bapak Casta adalah wali kelas IV dan beliau adalah salah satu guru PNS. Berkaitan dengan Pemanfaatan Lingkungan Sekolah Sebagai Sumber Belajar IPA, bapak casta mengatakan sebagai berikut : "Untuk mata pelajaran IPA dikelas IV, saya suka menggunakan lingkungan sebagai salah satu sumber belajar untuk siswa, walaupun tidak diterapkan pada semua materi sih neng. Hanya pada materi- materi tertentu saja, soalnya kan pelajaran IPA itu erat kaitanya dengan lingkungan alam"( Wawancara dengan bapak Casta S.Pd SD, kamis 25 april 2019 ).

Pernyataan selanjutnya dituturkan oleh salah satu siswa kelas IV yang bernama Aurel Lia pada hari Sabtu 18 mei 2019, terkait dengan Pemanfaatan Lingkungan Sekolah Sebagai Sumber Belajar IPA, Cika mengatakan : "Kalau sedang belajar IPA itu pak guru kadang sering mengajak untuk belajar di luar kelas, soalnya kata pak guru media yang mau digunakannya ada di lingkungan sekolah. tapi kadang juga pak guru membawa media nya dari lab, terus dipraktekin diluar kelas".

Hal ini dinyatakan pula oleh Cika Laudya selaku salah satu siswa kelas IV, Cika mengatakan hal yang serupa dengan Aurel Lia : "Kalo lagi belajar IPA teh lumayan sering belajar diluar kelas “. Hal ini didukung dengan pernyataan dari peneliti pada saat melakukan observasi dikelas IV pada hari Senin 29 April 2019, yang saat itu sedang melakukan pembelajaran IPA. Saat pembelajaran IPA guru wali kelas IV, Bapak Casta S.Pd SD menjelaskan materi tentang tumbuhan. Pada pembelajaran ini beliau terlihat mengajak siswa untuk belajar diluar kelas , tepatnya di halaman depan kelas IV. Beliau mengajak siswa untuk mengamati tumbuhan secara langsung. Dengan mengajak siswa belajar dilingkungan sekolah bisa memberikan pengalaman nyata / kongkret. 


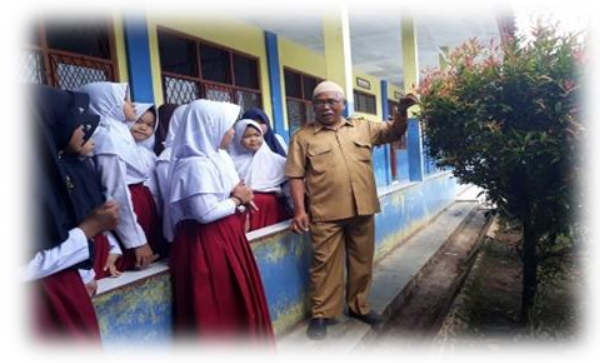

Gambar 4.1 Proses KBM Pembelajaran

\section{IPA}

Dari ketiga pernyataan dan hasil observasi tersebut dapat disimpulkan bahwa dalam penggunaan lingkungan sekolah sebagai sumber belajar siswa pada mata pelajaran IPA dikelas IV sudah di terapkan, walaupun tidak digunakan pada semua materi. Karena dengan memanfaatkan lingkungan sebagai sumber belajar, memungkinkan siswa mendapatkan pengalaman nyata, sehingga proses pembelajaran menjadi lebih optimal.

Guru mempunyai tanggung jawab untuk melihat segala sesuatu yang terjadi selama kegiatan pembelajaran untuk membantu proses perkembangan siswa. Kesempatan belajar semakin terbuka melalui berbagai sumber dan media. Guru hanya merupakan salah satu diantara berbagai sumber dan media belajar. Oleh karena itu selain kreativitas guru dalam mengelola pembelajaran, diperlukan juga faktor pendukung yang bisa menunjang keberhasilan proses pembelajaran.

Berdasarkan informan yang didapatkan, berkaitan dengan faktor pendukung dalam pemanfaatan lingkungan sekolah sebagai salah satu sumber belajar. Berikut penuturan dari bapak Casta S.Pd SD selaku wali kelas IV. "Salah satu faktor pendukung dalam pemanfaatan lingkungan sekolah sebagai sumber belajar yang ada di SDN I Cileuya adalah dengan adanya lingkungan sekolah yang asri dengan menanam dan merawat tumbuhan disekitar sekolah, yang kemudian nantinya bisa di manafaatkan sebagai salah satu sumber belajar bagi siswa". Selain itu saya juga selalu membimbing dan mendidik siswa untuk mampu berpikir dan bertindak kreatif dengan berbagai cara yang dilakukan melalui pemanfaatan lingkungan sekolah dengan baik dan benar sesuai dengan materi dan sesuai dengan kemampuan siswa. " ( Wawancara dengan bapak Casta S.Pd SD, kamis 25 april 2019 ).

Hal ini didukung dengan pernyataan dari peneliti pada saat melakukan observasi di SDN I Cileuya pada hari Senin 29 April 2019, Terlihat memang lingkungan sekolah disana terbilang cukup asri. Dengan adanya tumbuhan yang tertata rapih disekitar halaman depan sekolah dan jarangnya terlihat sampah yang berserakan yang membuat suasana lingkungan sekolah menjadi lebih asri dan rindang.

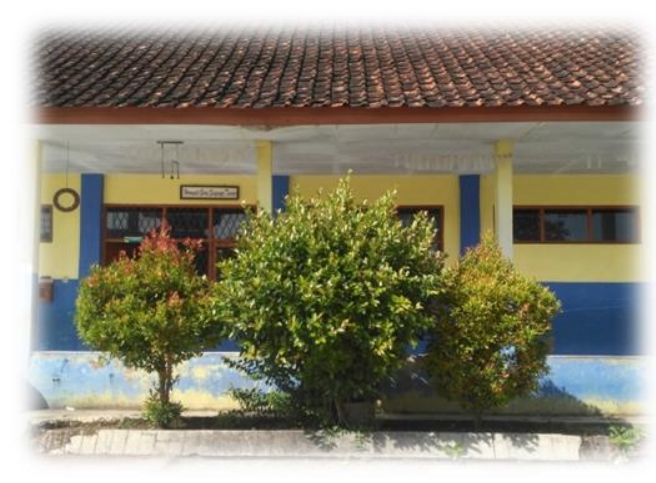

\section{Gambar 4.2 \\ Lingkungan halaman depan kelas yang asri}

Berdasarkan hasil observasi diatas dapat dijelaskan bahwa faktor pendukung dalam proses pemanfaatan lingkungan sekolah dalam pembelajaran IPA di SDN I Cileuya yaitu, dengan adanya lingkungan yang asri dan tumbuhan hijau yang ada disekitar lingkungan sekolah. Seperti ditaman dan halaman sekolah, ditambah juga keadaan lingkunganya bersih Selain itu guru selalu membimbing dan mendidik siswa untuk mampu berpikir dan bertindak 


\section{Jurnal Lensa Pendas, Vol. 5 Nomor 2 Tahun 2020, HIm 15 - 23}

Firda Sari Ayuningsih ${ }^{1}$, Irfan Fajrul Falah ${ }^{2}$

kreatif dengan berbagai cara yang dilakukan melalui pemanfaatan lingkungan sekolah dengan baik dan benar sesuai dengan materi dan sesuai dengan kemampuan siswa.

Lingkungan tempat tinggal dan sekolah merupakan bagian yang tak terpisahkan dari aktivitas keseharian siswa. oleh sebab itu, lingkungan dapat dimanfaatkan sebagai sarana untuk mengembangkan kemampuan- kemampuan siswa dalam proses pembelajaran. Menurut Gagne ( Dahar 2008 : 105) menyatakan bahwa " Lingkungan mempunyai peranan yang penting dalam pembentukan konsep, karena peranannya sebagai stimulus untuk terjadi suatu respon. Dengan kata lain, pembentukan sikap dan pengembangan keterampilan siswa ditentukan pula oleh interksinya dengan lingkungan".

Pada saat proses pembelajaran IPA dengan memanfaatkan lingkungan sekolah sebagai sumber belajar siswa di SDN I Cileuya, disitulah peran lingkungan sebagai sumber belajar berada. Seperti yang terlihat saat observasi dikelas IV pada hari Senin 29 April 2019, pada saat itu guru mengajak siswa belajar dihalaman depan kelas dengan menggunakan media belajar yaitu tumbuhan.

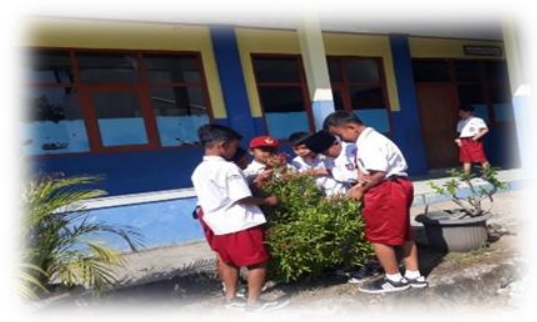

Gambar 4. 3

Pengamatan langsung siswa terhadap tumbuhan

Dengan demikian lingkungan sekolah mempunyai peran penting dalam proses pembelajaran, khususnya pembelajaran IPA yang memang erat kaitanya dengan lingkungan sekitar. Seperti hal nya menurut Darmodjo, (2011 : 65) yang mengatakan bahwa bahwa lingkungan dapat dijadikan sebagai sarana belajar, sumber belajar , maupun sebagai sasaran belajar.

1. Lingkungan sebagai sarana belajar

Yaitu karena dalam proses belajar pasti memerlukan sarana belajar seperti, misal ruang kelas dengan perabotanya, laboratorium dengan perlengkapanya, perpustakaan dan sebagainya. Lingkungan sebagai sarana belajar yang baik, bahkan lingkungan sekitar yang alami menyediakan bahan-bahan yang tidak usah dibeli.

2. Lingkungan sebagai sumber belajar

Semakin lingkungan tersebut digali, semakin banyak yang kita dapatkan, tidak saja bagi IPA itu sendiri tetapi juga berupa sumber dari berbagai ilmu pengetahuan seperti IPS dan Matematika.

3. Lingkungan sebagai sasaran belajar

Adalah segala sesuatu disekitar anak itu yang merupakan obyek untuk dipelajari/ diajarkan kepada anak, atau lingkungan sebagai sarana belajar bagi anak, misalnya kita mempelajari tumbuhan, struktur tanah, hewan atau manusia. Untuk mempelajari materi diatas maka kita memerlukan tumbuhan, hewan, manusia atau lahan yang ada di lingkungan sekitar.

Banyak keutungan yang diperoleh dari kegiatan mempelajari lingkungan dalam proses belajar mengajar. Kegiatan belajar mengajar akan lebih menarik dan tidak membosankan siswa duduk dikelas berjam- jam sehingga motivasi belajar siswa akan lebih tinggi. Seperti yang di katakan oleh Cika Laudya selaku siswa kelas IV, Cika mengatakan : “ Tentu saja lebih menarik, soalnya belajar diluar kelas itu tidak cepat mengantuk dan kita bisa belajar sambil bermain"

Gambar 4. 4 Pengamatan langsung siswa terhadap tumbuhan

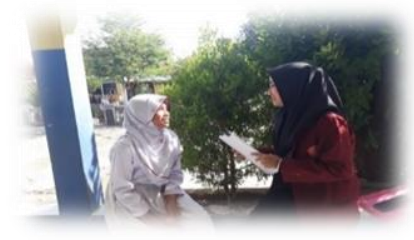

Dengan menekankan kegiatan 


\section{Jurnal Lensa Pendas, Vol. 5 Nomor 2 Tahun 2020, HIm 15 - 23}

Firda Sari Ayuningsih ${ }^{1}$, Irfan Fajrul Falah ${ }^{2}$

pembelajaran yang dikaitkan dengan situasi nyata, akan dapat memperluas wawasan berfikir siswa yang dan membangkitkan semangat siswa dalam belajar. Pemanfaatan lingkungan sekolah memang sangatlah berperan penting dan sangat menarik perhatian siswa dalam pembelajaran khususnya pada mata pelajaran IPA. Dan dengan diterapkanya pendekatan/ pemanfaatan lingkungan sekolah sebagai salah satu sumber belajar bisa memungkinkan tumbuhnya kebiasaan positif pada diri siswa bahkan guru sekalipun.

Dari beberapa pernyataan diatas dapat disimpulkan bahwa Pemanfaatan lingkungan sekolah memang sangatlah berperan penting dan sangat menarik perhatian siswa dalam pembelajaran khususnya pada mata pelajaran IPA. Sebab dengan memanfaatkan lingkungan sebagai sumber belajar dapat memotivasi belajar siswa sehingga siswa tidak cepat merasa bosan dalam mengikuti pembelajaran, dapat membuat siswa menjadi lebih aktif dalam pembelajaran, dengan begitu dapat tercipta suasana belajar yang menyenangkan, siswa mampu mengembangkan kemampuanya sendiri, siswa akan lebih berperan aktif dalam pembelajaranya dam mampu mengembangkan pengetahuanya serta mendapatkan informasi baru, yang sebelumnya tidak diketahuinya. Selain itu dengan memanfaatkan lingkungan sebagai sumber belajar siswa dapat menumbuhkan kebiasaan - kebiasaan positif pada diri siswa diantaranya sikap peduli terhadap lingkungan yang ada disekitar sekolah maupun lingkungan sekitar rumahnya.

\section{SIMPULAN}

Dalam proses pembelajaran Ilmu Pengetahuan Alam (IPA) dikelas IV SDN I Cileuya ini sudah menerapkan / memanfaatkan lingkungan sekolah sebagai salah satu sumber belajar siswa, yaitu dengan guru mengajak siswa untuk belajar diluar ruangan kelas seperti dihalaman dan taman sekitar sekolah. Dengan belajar dilingkungan sekolah dapat memungkinkan siswa mendapatkan pengalaman nyata, dan proses pembelajaran menjadi lebih optimal . Hal ini juga didukung dengan adanya lingkungan yang asri dan nyaman untuk digunakan sebagai sumber belajar siswa, ini dikarenakan guru selalu mencontohkan kepada siswa untuk selalu menjaga kebersihan lingkungan sekitar agar keasrianya tetap terjaga. Hal ini juga dibantu oleh kepala sekolah serta karyawan lainya demi terwujudnya tujuan yang diharapkan. Selanjutnya lingkungan Sekolah mempunyai peran penting dalam proses pembelajaran, khususnya pembelajaran IPA yang memang erat kaitanya dengan lingkungan sekitar. Karena lingkungan dapat berfungsi sebagai sasaran belajar, sumber belajar maupun sarana belajar IPA. Kegiatan belajar mengajar akan lebih menarik karena mereka bisa belajar sambil bermain, belajar tidak mudah bosan, mudah dimengerti dan yang lebih menyenangkan lagi dalam belajar khususnya mata pelajaran IPA, mereka bisa berinteraksi langsung dengan lingkungan alam sekitar. Dengan pembiasaan menggunakan sumber belajar yang ada disekitar lingkungan sekolah akan menumbuhkan sikap positif dari diri siswa bahkan guru dan kepala sekolah sekalipun, salah satunya adalah dapat menumbuhkan rasa cinta terhadap lingkungan.

\section{DAFTAR PUSTAKA}

Dahar, R.W. 2008. Teori-Teori Belajar. Jakarta : Erlangga

Djanali. 2007. Model Pembelajaran Kooperatif. Departemen Pendidikan Nasional Jakarta 


\section{Jurnal Lensa Pendas, Vol. 5 Nomor 2 Tahun 2020, HIm 15 - 23}

Firda Sari Ayuningsih ${ }^{1}$, Irfan Fajrul Falah ${ }^{2}$

Darmodjo, Hendro. 2011. Pendidikan IPA

II. Jakarta : Depdikbud

Hatimah, Ihat. 2007. Penelitian Pendidikan.

Bandung : UPI Press

Moleong, Lexy J. 2007. Metode Penelitian

Kualitatif. Bandung : PT Remaja

Rosdakarya

Mudlofir, Ali. 2015. Desain Pembelajaran Inovatif. Jakarta : PT Raja Grafindo Persada.

Narimawati, Umi. 2008. Metodologi

Penelitian Kualitatif dan Kauntitatif. Bandung : Agung Media

Rusman, 2014. Model - Model Pembelajaran (Mengembangkan Profesionalisme Guru). Jakarta : Raja Grafindo Persada.

Tatang, 2012. Ilmu Pendidikan. Bandung : CV. Pustaka Setia. 